\title{
Effect of Over-Pressure on Pipeline Structural Integrity
}

\author{
Igor MARTIĆ, Aleksandar SEDMAK, Nenad MITROVIĆ, Simon SEDMAK, Ivana VUČETIĆ
}

\begin{abstract}
The effect of proof over-pressure on pipeline structural integrity using fracture mechanics parameters is analysed in the case of pipeline in Reversed Hydro Power Plant, made of High Strength Low Alloyed steel with $800 \mathrm{MPa}$ tensile strength due to special design requirements. To assess its structural integrity, extensive testing of the full-scale prototype had been performed, including hydrostatic pressurizing. Since plastic strain was recorded during proof over-pressurizing, special attention is given to the fact that this is actually a mechanism for crack initiation and propagation. To investigate this effect micromechanical modelling is considered, as well as the Failure Assessment Diagramme. It is shown that over-pressuring has potential detrimental effect on pipeline safety, i.e. structural integrity.
\end{abstract}

Keywords: over-pressure; pipeline; structural integrity; risk matrix

\section{INTRODUCTION}

Pressure vessels and pipelines, made of High Strength Low Alloyed (HSLA) steels are usually welded using consumables with lower yield strength than Base Metal $(\mathrm{BM})$, as explained in more details in [1]. This combination of yield strength in a welded joint is known as Under Matching (UM), leaving Base Metal (BM) with elastic deformations only since eventual plastic strains develop in Weld Metal (WM), [1,2]. Therefore, plastic strain in WM is produced by stress lower than the BM yield strength, not to mention effect of over-loading. One should also keep in mind that stress in welded joints typically has non-uniform distribution because of stress concentration even if residual stresses are released. Therefore, simultaneously introduced different effects make stress calculation of welded joints difficult, so that pressure vessels' design becomes more complicated than usual. Sometimes, it is inevitable to test the produced pressure vessel as the full-scale model, in order to assess the behaviour of welded joints under different service conditions.

Reversible Hydro Power Plant (RHPP) "Bajina Basta" is in operation since 1982, [2]. Taking into account that the failure of the most critical part, the pipeline (Fig. 1), would cause water overflow of the surge hub in the surrounding area, and the collapse of the entire plant, it is clear that special attention is still needed to prove its structural integrity [3]. One of the most important effects is the proof testing, i.e. over-pressure, which is the main concern in this paper. Namely, there is a history of welded joint failures due to proof testing, e.g. spherical pressure vessels for liquefied natural gases [4], caused by unnecessary plastic deformation acting as crack initiation and propagation mechanism. Some details are given here, and more details can be found in [3].

Spherical pressure vessels are made of HSLA steel, brand name NIOVAL 47, thickness $20 \mathrm{~mm}$, nominal yield strength $R_{\mathrm{p} 0.2}=470-506 \mathrm{MPa}$, tensile strength $R_{\mathrm{m}}=639$ $660 \mathrm{MPa}$, elongation at fracture $\delta_{5}=25-27 \%$ and impact toughness $120-166 \mathrm{~J} / \mathrm{cm}^{2}$ at $0{ }^{\circ} \mathrm{C}$. Spherical pressure vessels are made by submerged arc welding (SAW) and shielded manual arc welding (SMAW). The following events tests were performed [3]:

- $\quad$ The first proof test with $p=12$ bar, Nov. 1976, no data.
- The second proof test (Sep. 1983), no leakage recorded.

- $\quad$ The third proof test, Apr. 1987, no leakage recorded. Ultrasonic test revealed no indication.

- The fourth proof test, Oct. 1989, as a special inspection required by the Inspection Office, no leakage recorded, but large number of cracks detected. After the repair, no cracks were found.

- The fifth proof test, Oct. 1989, also as a special inspection procedure, no leakage recorded, again a large number of cracks were detected, but still without crack after repair.

- Finally, in March 1991 large number of cracks were found in 331 locations, on the inner spherical storage tank side.

All data about this problem is given in [3], together with the conclusion that the pressure proof test, if applied as the over-pressure, causes new cracks in welded joints, whereas in new welded joints (performed during repairing) no cracks were produced. Therefore, it is the aim of this paper to provide more detailed explanation of the mechanisms by which proof pressure initiates cracks and why it makes more damage than benefits.

\section{RHPP BAJINA BASTA - PIPELINE DESIGN AND EXPERIMENT}

RHPP "Bajina Bašta" presents new modified plant with a very high flexibility, i.e. high guaranteed power and large amount of accumulated energy from hydro power station, [4]. One of the crucial components is the pipeline, Fig. 1. Having in mind the importance of pipeline, special design procedure has been used, combined with extensive testing of the full-scale prototype, Fig. 2, including static, dynamic and fracture mechanics testing, based on the following reasoning [2,5]:

1) Use of common structural steel (yield strength 350 $\mathrm{MPa}$ ) required unacceptable expensive solution with two pipelines and two tunnels.

2) In order to make only one pipeline, yield strength had to be at least $700 \mathrm{MPa}$. Therefore, SUMITEN HT80 was chosen, quenched and tempered weldable HSLA steel, with yield strength above $750 \mathrm{MPa}$. 
3) Anyhow, selection of this steel lead to another problem, since the upper limit in plate fabrication was $47 \mathrm{~mm}$, reducing safety margin from prescribed 2,07 to only 1,7 . Therefore, local plastic strain could have been expected even without over-pressurizing.
Here attention is focused on hydrostatic proof testing of the model, performed in three stages:

1) Pressure loading and unloading from 0 to $3 \mathrm{MPa}$ to check the measuring system.

2) Pressure loading and unloading from 0 to $9.2 \mathrm{MPa}$, to reach the service hoop stress.

3) Pressure overloading (30\%) and unloading from 0 to 12.3 $\mathrm{MPa}$, as required by the regulation.

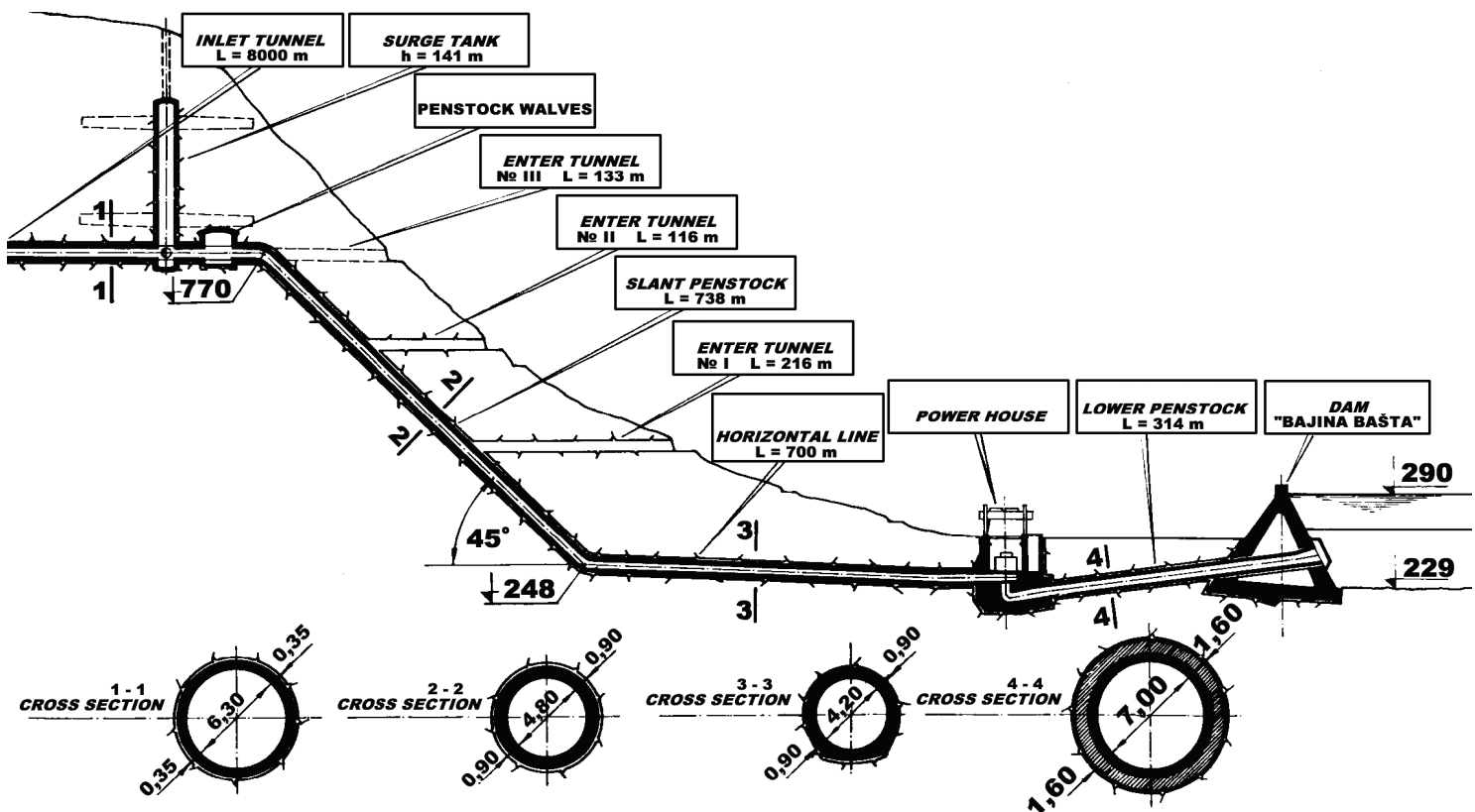

Figure 1 Disposition of penstock (upper and lower pipeline) "Bajina Bašta" [2, 3]
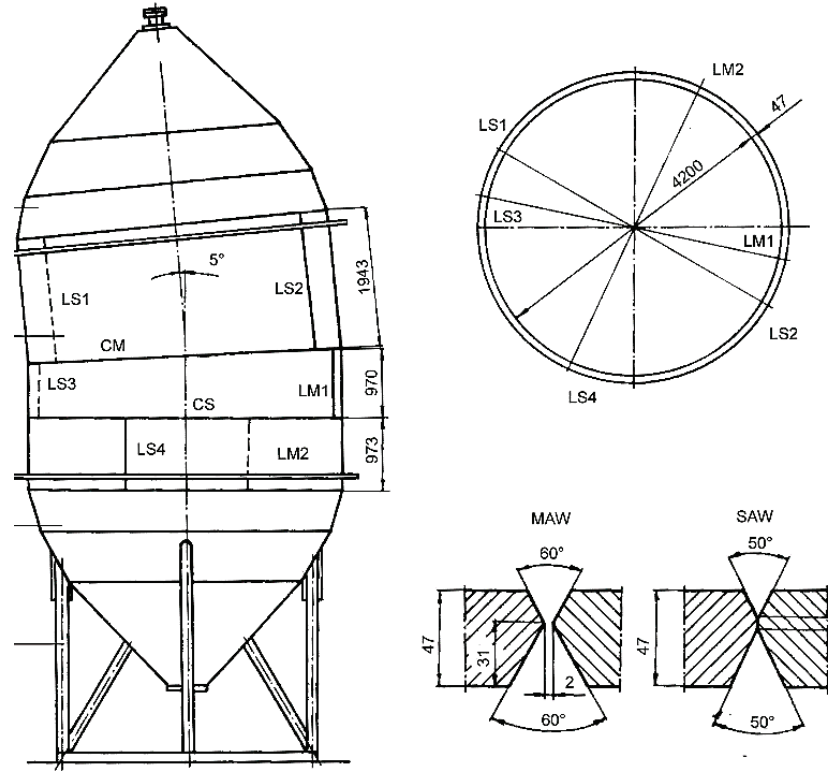

Figure 2 The full-scale model: L-Longitudinal, C-Circular; MAW - shielded manual arc welding (M); SAW-submerged arc welding $(\mathrm{S})[2,5]$

Full-scale model strains were measured by Strain Gages (SG) and Moiré grids, as described in details in [2, 5]. In BM response was dominantly elastic, whereas plastic strain $(0,24 \%)$ was registered in welded joint LS1 (SG2, SG34), indicating non-uniform, even strange behaviour due to stress concentration and weld mismatching, as defined in $[6,7]$ and shown in Fig. 3.

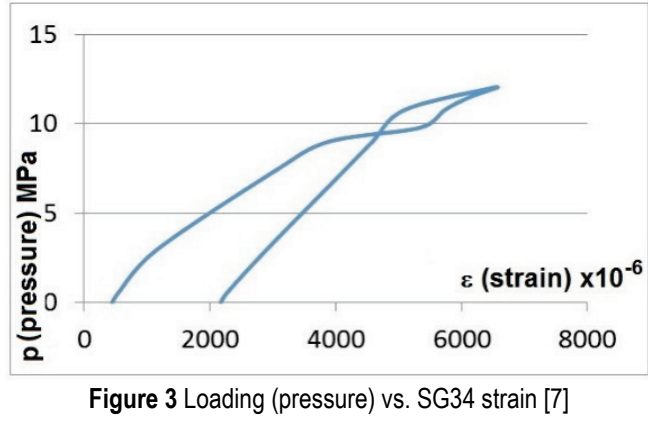

\section{NUMERICAL SIMULATION OF PIPELINE EXPERIMENT}

To explain such behaviour, numerical analysis was performed $[6,7]$ by using 3D elastic-plastic FE method, Fig. 4 (model) and Fig. 5 (stress concentration area).

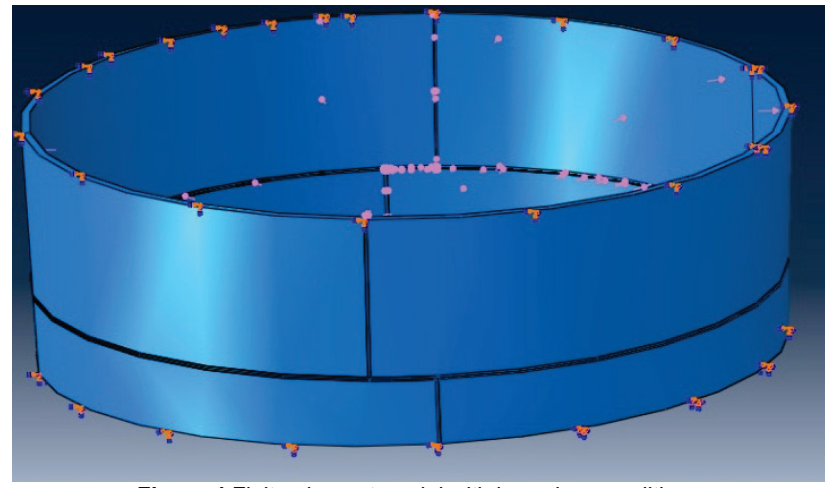

Figure 4 Finite element model with boundary conditions 


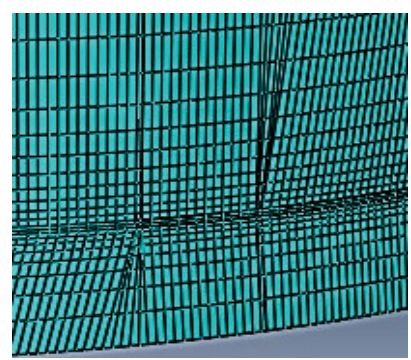

Figure 5 Finite element mesh of the full-scale model - stress concentration area

The resulting stress-strain behaviour is shown in Fig. 6 , indicating similar level of plastic strain, i.e. $0.3 \%$, whereas von Mises stress distribution in stress concentration area is shown in Fig. 7.

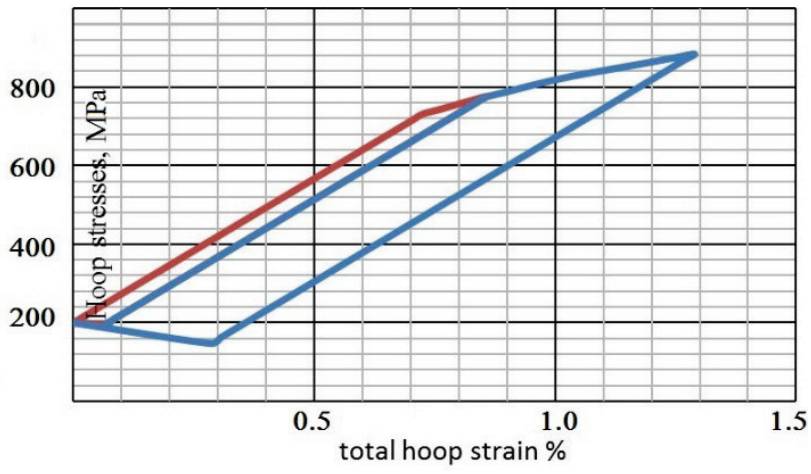

Figure 6 Numerical simulation of SG34 behaviour - hoop stress vs. strain

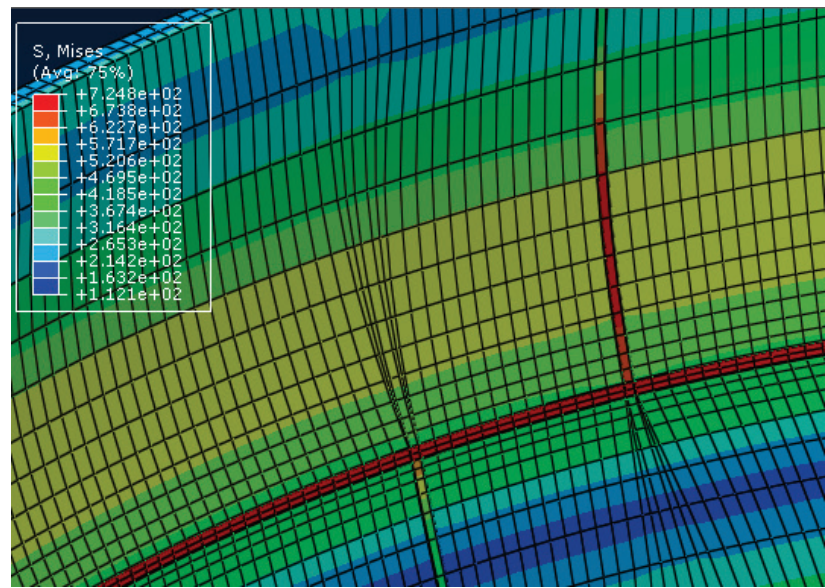

Figure 7 Von Mises stress distribution in the stress concentration area

Knowing that plastic deformation is the mechanism of crack initiation the evidence of plastic strain is actually the crucial argument that over-pressure is more detrimental than beneficial, as will be discussed later on. In order to explain better this phenomenon the micromechanical modelling of ductile fracture will be described briefly.

\section{MICROMECHANICAL MODEL OF DUCTILE FRACTURE}

Ductile fracture process can be represented as void nucleation, either around non-metallic inclusions or secondphase particles, or both, followed by their growth and coalescence. Thereby, void nucleates when so-called critical stress is reached either within inclusion or at inclusionmatrix interface, [8].

When loading is being increased, these materials exhibit strain hardening, until effect of voids prevail when softening starts to dominate. Researchers have recently introduced so- called coupled models of damage, with damage parameter being the essential part of the numerical procedure, enabling its evaluation during the finite elements (FE) analysis. One of the most successful coupled models is so-called CGM (Complete Gurson Model), [8], developed by incorporating the Thomason's limit load criterion into the GursonTvergaard-Needleman (GTN) micromechanical model, [9]. To start with, the void volume fraction $f$ is introduced into the plastic potential:

$\varphi=\frac{3 \sigma_{i j}^{\prime} \sigma_{i j}^{\prime}}{2 \sigma_{\mathrm{YS}}^{2}}+2 q_{1} f^{*} \cosh \left(\frac{3 q_{2} \sigma_{\mathrm{m}}}{2 \sigma_{\mathrm{YS}}}\right)-\left[1+\left(q_{1} f^{*}\right)^{2}\right]=0$

where $\sigma_{\mathrm{Ys}}$ is the yield stress, $\sigma_{i j}^{\prime}$ the stress deviator, $\sigma_{\mathrm{m}}$ is the mean stress, $q_{1}$ and $q_{2}$ Tvergaard's parameters and $f^{*}$ is a function of the void volume fraction:

$f^{*}= \begin{cases}f & \text { for } f \leq f_{\mathrm{c}} \\ f_{\mathrm{c}}+K\left(f-f_{\mathrm{c}}\right) & \text { for } f>f_{\mathrm{c}}\end{cases}$

where $f_{\mathrm{c}}$ is the critical value for void coalescence.

To quantify ductile fracture initial phase, one needs to evaluate the volume fraction of non-metallic inclusions, $f_{\mathrm{V}}$. This important parameter can be determined using light microscopy, After initial phase, increase of the void volume fraction should be quantified, taking into account the contribution of two phenomena, namely growth of existing voids and nucleation of new voids.

Criterion for the onset of void coalescence, according to CGM, can be defined as follows:

$$
\frac{\sigma_{1}}{\sigma}=\left(\alpha\left(\frac{1}{r}-1\right)+\frac{\beta}{\sqrt{r}}\right)\left(1-\pi r^{2}\right)
$$

where $r_{1}$ is the maximum principal stress, $a$ and $b$ are constants fitted by Thomason, $(a=0.1$ and $b=1.2)$. Zhang et al. [8] assumed a linear dependence of $a$ on hardening exponent $\mathrm{n}$, and applied it in the CGM. Taking the void space ratio $r$ as given in [8], the critical void volume fraction $f_{\mathrm{c}}$ can be calculated during the FE procedure, i.e. it is not a material constant, since it depends on the strain field and may have different value in different areas of the FE model. This fact is especially important for heterogeneous materials because of large stress and strain gradients around the crack tip, [10].

Micromechanical modelling of ductile fracture has been successfully applied in many practical problems, including welded joints, [10], providing good agreement with experimental results. Based on this experience, one can assume that the recorded or calculated plastic strain $(0.24-0.3 \%)$ is high enough to initiate a crack.

It is very important to understand the mechanism of crack initiation and growth, precisely defined and well described by the most recent complete GTN model, as one of the crucial arguments to prove detrimental effects of over-pressurizing.

\section{FAILURE ASSESSMENT DIAGRAM}

Another aspect of this analysis is application of the Failure Assessment Diagramme (FAD), as shown in Fig. 8. 
The FAD is based on simultaneous consideration of brittle fracture and plastic collapse, as to major mechanisms of failure of statically loaded steel structures, such as pressure vessels. Both failure mechanisms are represented as nondimensional ratios of working parameters and material properties. This approach has been applied recently to estimate risk probability $[11,12]$ based on simple reasoning that the closer the point is to the limit curve the larger is the probability of failure. The limit curve is defined according to Dugdale model:

$$
K_{r}=S_{r}\left[\frac{8}{\pi^{2}} \ln \sec \left(\frac{\pi}{2} S_{r}\right)\right]^{-\frac{1}{2}}
$$

The points are calculated for surface crack with length of $90 \mathrm{~mm}$ and depth equal to $1 / 4$ of thickness, as explained in [11], leading to the point in the safe region with coordinates $(0,5 ; 0,91)$, where 0.5 corresponds to the ratio of hoop stress caused by design pressure and mid-value of yield and tensile strength, whereas 0,91 corresponds to the weld metal $K_{\mathrm{I}} / K_{\text {Ic }}$ value. Anyhow, in the case of $30 \%$ overpressure, this point is shifted to unsafe region since its coordinates become $(0,65 ; 0,91)$, Fig. 8 . In this simple way, one can also show detrimental effect of over-pressure, as already shown with more sophisticated, micromechanical modelling.

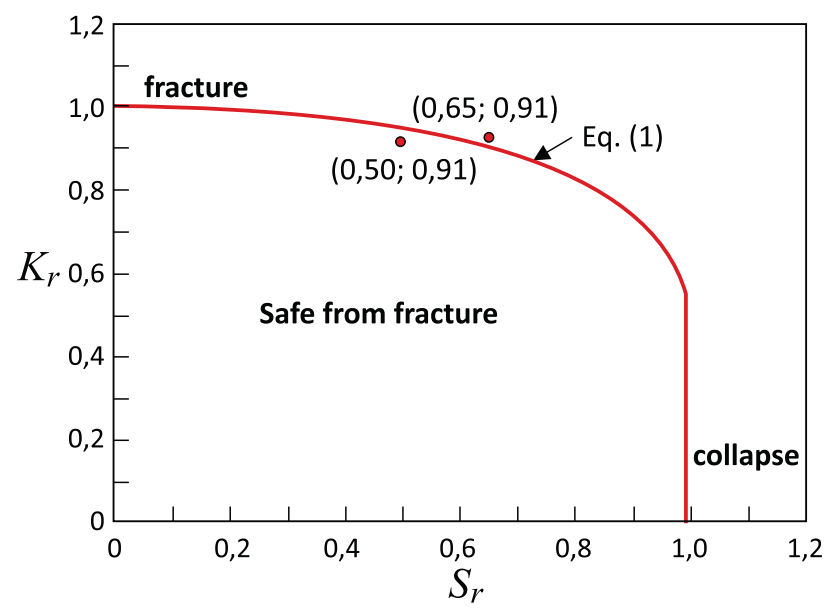

Figure 8 Failure assessment diagramme for RHBB pipeline

\section{CONCLUSIONS}

It is shown, using different approaches, that the effect of over-pressure is detrimental from the point of view of structural integrity of pipeline in RHPP. Two approaches, one more sophisticated (micromechanical modelling), and the other, simpler one (FAD), lead to the same conclusion that proof over-pressure is unnecessary challenge to the safety of the critical component in a very important power plant.

Having in mind the importance of this topic, we recommend more detailed analysis in the future work, especially regarding more precise correlation between the plastic strain level and initiation of crack, as predicted by the micromechanical modelling.

\section{REFERENCES}

[1] Gubeljak, N., Predan, J., Rak, I., \& Kozak, D. (2009). Integrity assessment of HSLA steel welded joint with mismatched strength. Structural Integrity and Life, 9, 157-164.

[2] Sedmak, A., Sedmak, S., \& Milovic, Lj. (2011). Pressure Equipment Integrity Assessment by Elastic-Plastic Fracture Mechanics Methods. Monograph, Society for Structural Integrity and Life (DIVK), Belgrade.

[3] Vučetić, I., Kirin, S., Vučetić, T., Golubović, T., \& Sedmak, A. (2018). Analiza rizika u slučaju havarije rezervoara za vazduh u RHE Bajina Bašta. Structural Integrity and Life, 18, 3-6.

[4] Golubović, T., Sedmak, A., Spasojević Brkić, V., Kirin, S., \& Veg, E. (2018). Welded joints as critical regions in pressure vessels - case study of vinyl-chloride monomer storage tank. Hemijska industrija, 72(4), 177-182. https://doi.org/10.2298/HEMIND171009006G

[5] Sedmak, S. \& Sedmak, A. (2005). Integrity of Penstock of Hydroelectric Powerplant. Structural Integrity and Life, 5, 5970.

[6] Mahdi, A. (2015). Initial plastic deformations and residual stresses influencing the welded joint behaviour in the presence of cracks, PhD thesis, Faculty of Mechanical Engineering, University of Belgrade.

[7] Mahdi A., Sedmak A., Petrovski B., Tatić U., Sedmak S., \& Djurdjevic A. (2012). Quality Assurance of a Large Welded Penstock Manufacturing by Means of Full-scale Model Testing. Proc. ICMEM, Presov, 107-108

[8] Zhang, Z. L., Thaulow, C., \& Ødegard. J. (2000). A complete Gurson model approach for ductile fracture. Eng. Fract. Mech. 67, 155-168. https://doi.org/10.1016/S0013-7944(00)00055-2

[9] Tvergaard, V. \& Needleman, A. (1984). Analysis of the cupcone fracture in a round tensile bar. Acta Metallurgica, 32, 157-169. https://doi.org/10.1016/0001-6160(84)90213-X

[10] Younise, B., Rakin, M., Gubeljak, N., Medjo, B., \& Sedmak, A. (2011). Numerical simulation of constraint effect on fracture initiation in welded specimens using a local damage model. Structural Integrity and Life Journal, 11, 51-56

[11] Golubović, T., Sedmak, A., Spasojević Brkić, V., Kirin, S., \& Rakonjac, I. (2018). Novel risk based assessment of pressure vessels integrity. Tehnički vjesnik, 25(3), 803-807. https://doi.org/10.17559/TV-20170829144636

[12] Sedmak A., Algool, M., Kirin, S., Rakicevic, B., \& Bakic, R. (2016). Industrial safety of pressure vessels - Structural integrity point of view. Hemijska industrija, 70(6), 685-694. https://doi.org/10.2298/HEMIND150423005S

\section{Contact information:}

\section{Igor MARTIĆ, Ph.D. student}

Innovation Center of the Faculty of Mechanical Engineering,

Kraljice Marije 16, 11020 Belgrade 35, Serbia

\section{Aleksandar SEDMAK, Professor PhD}

University of Belgrade, Faculty of Mechanical Engineering

Kraljice Marije 16, 11020 Belgrade 35, Serbia

asedmak@mas.bg.ac.rs

Nenad MITROVIĆ, Assistant Professor, Ph.D.

University of Belgrade, Faculty of Mechanical Engineering,

Kraljice Marije 16, 11020 Belgrade 35, Serbia

Simon SEDMAK, Ph.D. student

Innovation Center of the Faculty of Mechanical Engineering

Kraljice Marije 16, 11020 Belgrade 35, Serbia

Ivana VUČETIĆ, Ph.D. student

Innovation Center of the Faculty of Mechanical Engineering,

Kraljice Marije 16, 11020 Belgrade 35, Serbia 